\title{
Implementasi Permainan Tradisional Gobag Sodor Dalam Mengembangkan Motorik Kasar Anak Usia Dini(Studi Kasus Di Tk Pertiwi 2 Sidodadi Kecamatan Pekalongan Kabupaten Lampung Timur)
}

\author{
Adek Diah Saputri, ${ }^{1}$ Dian Eka Priyantoro, ${ }^{2}$ Uswatun Hasanah $^{\mathbf{3}}$ \\ Institut Agama Islam Negeri Metro Lampung, Indonesia ${ }^{123}$ \\ Email: adekdiahsaputri@gmail.com ${ }^{1}$, diansari319@gmail.com², \\ uswahdeini@gmail.com ${ }^{3}$
}

\begin{tabular}{|c|c|}
\hline Abstract & \\
\hline $\begin{array}{l}\text { Gross motor skills are body movements that use large } \\
\text { muscles throughout the body which will be affected by } \\
\text { the maturity of the child. Encouragement when the } \\
\text { child runs, jumps, stands on one leg, climbs, plays and } \\
\text { throws a ball, rides a tricycle or four wheel. Motor } \\
\text { development is the development of controlling physical } \\
\text { movements through coordinated activities of the nerve } \\
\text { center, nerves, and muscles. The traditional game } \\
\text { Gobag Sodor comes from the words Gobag and Sodor. } \\
\text { The word Gobag which means to move freely. As for } \\
\text { Sodor, it means Spear. The gobag sodor game is } \\
\text { usually played in an open field. The play area is } \\
\text { rectangular or circular and is lined inside. The } \\
\text { traditional game of Gobag Sodor as a form of play } \\
\text { activity is believed to provide benefits for children's } \\
\text { physical and mental development. The purpose of this } \\
\text { study was to find out how the implementation of the } \\
\text { Gobag Sodor traditional game in developing gross } \\
\text { motor skills for early childhood. Based on the results of } \\
\text { research and discussion on the Implementation of the } \\
\text { Gobag Sodor Traditional Game in Developing Gross } \\
\text { Motoric Early Childhood in TK Pertiwi } 2 \text {, Sidodadi } \\
\text { Village, Pekalongan District, East Lampung Regency, } \\
\text { the results showed good results. The implementation } \\
\text { of the Gobag Sodor traditional game in developing } \\
\text { gross motor development in this case children can } \\
\text { further develop gross motor optimally. Like a child is } \\
\text { able to run while jumping, balance body movements, } \\
\text { cooperate and coordinate all bodies }\end{array}$ & $\begin{array}{r}\text { Keywords: } \\
\text { Gross Motoric } \\
\text { Development; } \\
\text { Gobag Sodor } \\
\text { Traditional Games. }\end{array}$ \\
\hline Abstrak & \\
\hline $\begin{array}{l}\text { Motorik kasar adalah gerakan tubuh yang } \\
\text { menggunakan otot-otot besar sebagian seluruh tubuh } \\
\text { yang akan dipengaruhi oleh kematangan anak. }\end{array}$ & $\begin{array}{l}\text { Kata Kunci: } \\
\text { Perkembangan } \\
\text { Motorik Kasar; }\end{array}$ \\
\hline
\end{tabular}


Dorongan saat anak berlari, melompat, berdiri di atas satu kaki, memanjat, bermain dan melempar bola, mengendarai sepeda roda tiga atau roda empat. Perkembangan motorik adalah perkembangan mengendalikan gerakan jasmani melalui kegiatan pusat syaraf, urat syaraf, dan otot yang terkoordinasi. Permainan tradisional Gobag Sodor berasal dari kata Gobag dan Sodor. Kata Gobag yang artinya bergerak bebas. Sedangkan untuk Sodor artinya Tombak. Permainan gobag sodor yaitu biasanya dimainkan dilapangan terbuka. Area bermainnya berbentuk persegi panjang atau lingkaran dan diberi garis didalamnya. Permainan tradisional Gobag Sodor sebagai salah satu bentuk dari kegiatan bermain diyakini dapat memberikan manfaat bagi perkembangan fisik dan mental anak. Tujuan dari penelitian ini adalah untuk mengetahui bagaimana Implementasi Permainan Tradisional Gobag Sodor dalam Mengembangkan Motorik Kasar Anak Usia Dini. Berdasarkan hasil penelitian dan pembahasan tentang Implementasi Permainan Tradisional Gobag Sodor dalam Mengembangkan Motorik Kasar Anak Usia Dini di TK Pertiwi 2 Desa Sidodadi Kecamatan Pekalongan Kabupaten Lampung Timur menunjukan hasil yang baik. Adanya implementasi permainan tradisional Gobag Sodor dalam mengembangkan perkembangan motorik kasar dalam hal ini anak-anak bisa lebih mengembangkan motorik kasar secara optimal. Seperti anak mampu berlari sambil melompat, menyeimbangkan gerakan badan, bekerjasama dan mengkoordinasi semua badan.

Diterima : 2 Juli 2021; Direvisi : 7 Agustus 2021; Diterbitkan: 28 Agustus 2021 http://doi.org/10.19105/kiddo.v2i2.4579

(c) (i) Kiddo Jurnal Pendidikan Islam Anak Usia Dini
This is an open access article under the CC-BY-NC license Institut Agama Islam Negeri Madura, Indonesia

\section{Pendahuluan}

Pendidikan dan pengembangan bagi Anak Usia Dini merupakan salah satu faktor penting yang perlu difikirkan dan dilaksanakan orangtua untuk mempersiapkan masa depannya yang baik. Pada masa usia dini, anak sangat peka ingatannya dan mudah untuk diberikan keterampilan yang dapat mengasah semua aspek perkembangannya terutama pada aspek motorik. Saat ini banyak di Indonesia yang kurang pengoptimalan terhadap perkembangan motorik kasar khususnya pendidikan anak usia dini. Perkembangan adalah serangkaian perubahan yang terjadi pada individu yang berlangsung 
secara sistematis, progresif, dan kontinu baik secara fisik dan psikis (Ahmad Rudiyanto, 2018:4).

Keterampilan motorik adalah gerakan-gerakan tubuh atau bagianbagian tubuh yang disengaja, otomatis, cepat dan akurat. Gerakangerakan ini merupakan rangkaian koordinasi dari beratus-ratus otot yang rumit. Ketrampilan motorik ini dapat dikelompokkan menurut ukuran otot-otot dan bagian-bagian badan yang terkait, yaitu keterampilan motorik kasar dan keterampilan motorik halus. Secara garis besarnya, urutan perkembangan keterampilan motorik ini mengikuti dua prinsip (Ahmad Rudiyanto, 2016:111).

Dunia anak merupakan dunia bermain, yang menjadi perhatian bagi pendidikan, psikolog, para ahli filsafat sejak zaman dahulu dan begitupula orangtua (Mansur, (2009: 149). Bermain merupakan kebutuhan alami bagi anak usia dini. Selain sebagai aktivitas bersenang-senang bermain juga sebagai sarana belajar bagi anak dan pengembangan aspeknya terutama pada aspek motoriknya ( $M$. Fadillah 2017:6). Permainan tradisional banyak tersebar diberbagai daerah indonesia salah satunya permainan tradisional Gobag Sodor. Gobag Sodor merupakan permainan yang dimainkan oleh kelompok yang melawan kelompok lainnya (Sholatul Hayati, 2018:145). Untuk bisa memenangkan dalam permainan tradisional gobag sodor, setiap orang harus terjaga dan lari secepat mungkin. Untuk itu diperlukan ketangkasan, kecepatan, serta kecerdikan. Di permainan tradisional gobag sodor sangat mengandalkan motorik kasar seperti berlari, melompat, mengkoordinasi badan ketika menghindar dari lawan agar badan tidak terkena oleh lawan, ketangkasan dan keseimbangan ketika berlari. Sehingga permainan ini sangat cocok sekali untuk mengembangkan motorik kasar anak usia dini (Mulyani, 2016:165). Permainan ini dimainkan dengan dua grup, yang masing-masing tim terdiri dari 3-5 orang. Laki-laki maupun perempuan dapat ikut bergabung dalam permainan ini. Inti dari permainan menghadang lawan agar tidak masuk atau lolos melewati garis baris terakhir secara bolak-balik, dan untuk meraih kemenangan semua anggota grup harus secara lengkap melewati area lapangan yang telah ditentukan (Julie Indah Rini, 2010:33). Inti permainannya yaitu menghadang lawan agar tidak bisa lolos melewati garis ke baris terakhir secara bolak balik, dan agar bisa meraih kemenangan seluruh anggota group secara lengkap melakukan proses balak-balik dalam ara lapangan (Uswatun Hasanah, 2019:46). Sebagaimana diketahui bersama selama rentang perkembangan anak usia dini anak banyak melakukan kegiatan bermain. Banyak permainan yang bisa dilakukan dan dicoba oleh anak terutama permainan tradisional jaman dahulu yang banyak sekali jenisnya, misalnya permainan gobak sodor, conglak, bentengan, petak 
umpet, lompat tali, kasti, egrang dan masih banyak yang lainnya. Mengembangkan perkembangan motorik kasar anak dapat dilakukan dengan salah satunya adalah dengan Permainan Tradisional Gobag Sodor.

\section{Metode}

Dalam penelitian ini menggunakan jenis penelitian kualitatif, yaitu penelitian yang mengungkapkan suatu fenomena melalui deskripsi bahasa non-statistik secara holistik dan melakukan penelitian tentang kejadian yang ada di lapangan. Dalam penelitian ini yang menjadi subjek adala kepala sekolah, guru, dan orangtua anak. Teknik pengumpulan data dalam penelitian ini menggunakan teknik observasi, wawancara dan dokumentasi. Teknin penjamin keabsahan menggunakan triangulasi teknik dan sumber. Serta, teknik analisis data pada penelitian ini yaitu Peneliti menggunakan teknik analisis data model milles dan hubermen tahapan teknik analisis data adalah, data reduction, data display, dan conclutation/verivication. Teknik analisis ini mempunyai tahapan yaitu dimulai data mengumpulakan data, dimana data yang diperoleh banyak maka perlu untuk dilakukan reduksi data, yaitu meneliti dan memilih data yang akan digunakan.

\section{Hasil dan Pembahasan}

\section{Pengertian Motorik Kasar Anak Usia Dini}

Motorik kasar adalah gerakan tubuh yang menggunakan otot-otot besar sebagian seluruh tubuh yang akan dipengaruhi oleh kematangan anak. Dorongan saat anak berlari, melompat, berdiri di atas satu kaki, memanjat, bermain dan melempar bola, mengendarai sepeda roda tiga atau roda empat. Perkembangan motorik adalah perkembangan mengendalikan gerakan jasmani melalui kegiatan pusat syaraf, urat syaraf, dan otot yang terkoordinasi (Ahmad Rudiyanto, 2016:10). Keterampilan motorik adalah gerakan-gerakan tubuh atau bagianbagian tubuh yang disengaja, otomatis, cepat dan akurat. Gerakangerakan ini merupakan rangkaian koordinasi dari beratus-ratus otot yang rumit. Ketrampilan motorik ini dapat dikelompokkan menurut ukuran otot-otot dan bagian-bagian badan yang terkait, yaitu keterampilan motorik kasardan keterampilan motorik halus. Secara garis besarnya, urutan perkembangan keterampilan motorik ini mengikuti dua prinsip.

a. Prinsip dari kepala ke ekor (chepalocaudal), menunjukkan urutan perkembangan, dimana bagian atas badan lebih dahulu berfungsi dan terampil digunakan sebelum bagian yang lebih rendah. Bayi terlebih dahulu belajar memutar kepalanya sebelum belajar 
menggerakkan kaki dengan sengaja, dan mereka belajar menggerakkan kaki.

b. Prinsip dari dekat ke jauh (proximodistal), menunjukkan perkembangan keterampilan motorik, dimana bagian tengah badan lebih dahulu terampil sebelum dibagian-bagian sekelilingnya atau bagian yang lebih jauh. Bayi belajar melambaikan keseluruhan lengannya sebelum belajar menggoyangkan pergelangan tangan dan jari-jarinya. Keterampilan motorik menjadi dua bagian, yaitu: a) keterampilan motorik kasar; b) keterampilan motorik halus. Keterampilan motorik kasar, meliputi keterampilan otot-otot besar lengan, kaki, dan batang tubuh, seperti berjalan dan melompat. Sedangkan, Keterampilan motorik halus, meliputi otot-otot kecil yang ada diseluruh tubuh, seperti menyentuh dan memegang (Uswatun Hasanah, 2016:721).

Perkembangan fisik motorik anak usia dini dapat diartikan sebagai perubahan bentuk tubuh pada anak yang berpengaruh terhadap keterampilan gerak tubuhnya (Novan Ardy Wiyani, 2014:35). Salah satunya yang harus di kembangkan oleh orangtua atau pendidik adalah motorik nya karena dalam pengembangan motorik terdapat banyak kegunaan yang harus distimulus seperti melompat, berlari, berjalan, menendang, dan lain-lain (Ahmad Rudiyanto, 2016:10). Motorik adalah gerakan yang dikendalikan otot-otot besar atau kasar dan yang dikendalikan otot-otot halus atau kecil. Dalam perkembangan fisik anak secara umum ketika usia 1 tahun seperti:

a. Anak mampu berjalan sendiri dan kaki mengangkang dan lengan yang naik untuk menjaga keseimbangan kaki

b. Sering terjatuh saat dalam posisi duduk

c. Dapat berdiri dan berlutut tanpa bantuan

d. Mengembangkan kemampuan menyeimbangkan diri

e. Dapat menuruni tangga, biasanya dengan merayap

f. Telah mampu berjalan sendiri tanpa terjatuh

g. Dapat melompat, menjongkok, serta memegang berbagai benda kemana-mana (Lia Ricka Pratama, 2017:109).

\section{Kemampuan Perkembangan Motorik Kasar}

Kemampuan perkembangan motorik kasar pada tahun-tahun pertama dan kedua ditandai dengan berjalan dengan lancar, berlari, naik turun tangga sendiri, dan dapat menendang bola. Kemudian pada tahun ketiga anak sudah mulai menunjukan peningkatan berupa berlari dengan baik, mengendarai sepeda roda tiga, berdiri dengan satu kaki secara singkat. Dan pada tahun keempat anak lebih optimal dalam perkembangan motorik kasarnya berupa anak mampu meloncat, melompat jauh, dan melempar bola dengan tangan ke atas (Lia Ricka Pratama, 2017:60). 


\section{Faktor-Faktor yang Mempengaruhi Perkembangan Motorik Kasar pada Anak}

Ada beberapa faktor yang mempengaruhi tumbuh kembang pada anak tentang masalah fisik motorik. Seperti:

a. Faktor keturunan (hereditas)

faktor dari keturunan banyak menjadi penyebab munculnya gangguan pada fisik karena hasil dari satu keturunan keturunan yang lain meskipun kadang bisa dari keluarga yang jauh pun. seperti tinggi badan, kecepatan dan pertumbuhan.

b. Nutrisi

Pemberian makanan yang bergizi oleh orangtua kepada anak usia dini sangat penting untuk memberikan energi pada anak yang sangat aktif di usia dini. Pemberian gizi atau nutrisi yang cukup dapat merangsang pertumbuhan dan perkembangan organ-organ tubuh manusia.

c. Faktor lingkungan yang baik atau merugikan kematangan fungsifungsi.

Faktor lingkungan sangat mempengaruhi masa perkembangan keterampilan motorik anak. Bisa dilihat sekian banyak perkembangan pengasuhan di dunia, sangat lah mempengaruhi perkembangan anak dari jasmani maupun rohani sangatlah berbeda. Karena itu, orangtua memberikan sarana lingkungan yang dapat mengembangkan semua aspek perkembanganya terutama motorik. (Penney Upton, 2012:61) Serta pola asuh yang baik dan sikap positif dari lingkungan serta masyarakat dapat menerima terhadap keberadaan anak akan menumbuhkan konsep diri positif bagi anak dalam menilai diri sendiri. Anak menilai dirinya sesuai dengan apa yang dialami dan didapatkan dari lingkungan. Anak dilatih untuk bersikap obyektif, dan menghargai diri sendiri dengan selalu berfikir positif untuk diri mereka sendiri (Jamiatul Muslimah, dkk, 2020:5).

\section{Metode Pengembangan Motorik Kasar Anak}

Metode merupakan cara agar suatu tujuan pembelajaran tertentu dapat tercapai. Agar bisa mengembangkan motorik kasar guru bisa menggunakan metode-metode yang nantinya akan menjamin anak tidak mengalami cidera dan menyesuaikan karakteristik anak TK ( $\mathrm{J}$. Beaty Janice, 2015:200).

\section{Pengertian Permainan Tradisional Gobag Sodor}

Istilah gobag sodor dikenal di daerah Jawa Tengah. Di Kepulauan Natuna dikenal dengan nama galah, di daerah Riau dikenal dengan galah panjang, di daerah Riau Daratan dikenal dengan nama Cak Bur atau Main Belon. Sedangkan, di Jawa Barat sendiri dikenal dengan nama Galah Asih, di Makasar disebut dengan Asing dan di daerah 
Batak Toba dikenal Margala. Banyak yang mengatakan permainan tradisional Gobag Sodor ini berasar dari Yogyakarta. Gobag Sodor berasal dari kata Gobag dan Sodor. Kata Gobag yang artinya bergerak bebas. Sedangkan untuk Sodor artinya Tombak (Irwan P. Ratu Bangsawan, 2019:39).

Awal mula permainan Gobag Sodor muncul karena dahulu kala para prajurid mempunyai permainan sodoran sebagai kegiatan latihan keterampilan dalam berperang. Sodor yaitu tombak dengan panjang kira-kira 2 meter, tanpa mata tombak yang tajam diujungnya. Sedangkan pendapat mengatakan pengertian lain dari permainan Gobag Sodor yaitu dari istilah bahasa asing, merupakan kata dari go back to door. Perubahan idiom tersebut ke dalam bahasa Jawa diakibatkan oleh penyesuaian lafal. kata go back to door tersebut dalam lidah jawa diucapkan 'go bag so dor' selanjutnya menjadi kata 'gobag sodor' (Moniqa Siagawati. Dkk, 2007:89 ). Gobag sodor adalah permainan yang memerlukan kerjasama tim dimana dalam permainan ini memerlukan gerakan berlari dan kelincahan yang dimainkan dilapangan. Permainan ini sangat hemat biaya dan tidak memerlukan alat (Meiriani Armen dan Apriyanti Rahmalia, 2017:326). Jenis permainan tradisional di Indonesia yang dapat dimainkan oleh anak, antara lain engklek, lompat tali, gobag sodor dan masih banyak lagi (Julie Indah Rini, 2010:36).

Bermain merupakan kebutuhan alami bagi anak usia dini. Selain sebagai aktivitas bersenang-senang bermain juga sebagai sarana belajar bagi anak dan pengembangan aspeknya terutama pada aspek motoriknya. Apapun kegiatannya, selama itu terdapat unsur kesenangan atau kebahagiaan untuk anak usia dini, maka bisa disebut sebagai bermain (M. Fadillah, 2017:6). Begitu pula dengan permainan tradisional dapat sebagai salah satu bentuk dari kegiatan bermain diyakini dapat memberikan manfaat bagi perkembangan fisik dan mental anak (Euis Kurniati, 2017:1). Adapun manfaat bermain dapat berpengaruh dalam diri anak, diantaranya mengembangkan otot dan melatih seluruh bagian tubuhnya, dapat melatih berkomunikasi, sebagai penyalur energi emosional yang terpendam, sebagai sumber belajar anak, dapat melatih standar moral anak, anak merasa terbebas dari segala tekanan, sehingga merasa anak keceriaan dan kegembiraan, memcoba dengan hal yang baru, dan melatih anak untuk memecahkan masalah yang sederhana (M. Fadillah, 2017:6).

Permainan tradisional banyak mengandung nilai-nilai pendidikan yang dapat menumbuhkan dan mengembangkan 9 kecerdasan (kemampuan) anak yaitu kecerdasan linguistik, logika matematika, visualspasial, musical, kinestetik, naturalis, interpersonal, dan spiritual dengan menggunakan strategi belajar sambil bermaian. Nilai Nilai-nilai 
pendidikan dalam permainan tradisional tersebut terkandung dalam permainan, gerak, syair lagu maupun tembangnya (Iis Nurhayati, 2012:40). Dari permainan tradisional dapat diambil beberapa nilai yang dapat ditanamkan nilai-nilai tersebut antara lain rasa senang, bebas, rasa berteman, demokrasi, penuh tanggung jawab, rasa patuh, rasa saling membantu, yang semuanya merupakan nilai-nilai yang sangat baik dan berguna dalam kehidupan masyarakat (Novi Mulyani, 2016:59).

\section{Cara Bermain Permainan Tradisional gobag sodor}

Permainan gobag sodor yaitu biasanya dimainkan dilapangan terbuka. Area bermainnya berbentuk persegi panjang atau lingkaran dan diberi garis didalamnya. Garis batas biasanya digambar dengan kapur jika dimainkan dilapangan bulu tangkis atau bisa juga menggambar ditanah. Cara bermain gobag sodor yaitu:

a. Anak-anak dibagi menjadi dua tim. Setelah menentukan tim mana yang jaga maka permainan bisa dimulai.

b. Anggota tim jaga harus menjaga dimasing-masing garis dan boleh bergerak sesuai sepanjang garis yang ditentukan untuk menyentuh anggota tim lawan.

c. Tim yang tidak berjaga harus bisa merobos garis-garis lawan tersebut tanpa tersentuh oleh tim yang menjaga.

d. Setelah berhasil menerobos harus kembali ketempat pertama. Jika berhasil akan mendapat nilai sedangkan jika terkena anggota badannya oleh lawan akan bergantian jaga.

e. Tim yang menang adalah yang mengumpulkan nilai paling banyak (Julie Indah Rini, 2010:36).

Penerapan permainan tradisional dapat mempengaruhi perkembangan motorik kasar anak (Khodijah, 2012:152). Seperti permainan gobak sodor ini juga dapat mengembangkan motorik kasar anak karena dalam permainan ini banyak gerakan dasar yang dilakukan anak seperti berlari, mengkoordinasi gerakan dan melompat (Lita Erdiana, 2016:12). Motorik kasar itu sendiri dapat diketahui merupakan gerakan jasmani berupa koordinasi gerakan tubuh pada anak, seperti melompat, bergantung, merangkak, berlari, berjinjit, melempar dan menangkap dan menjaga keseimbangan (Mursid, 2015:12.).

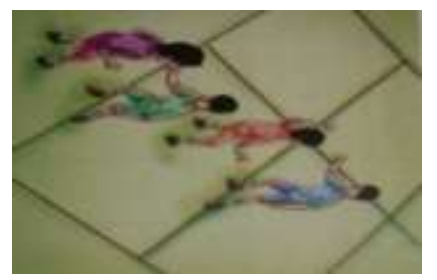

Gambar 2.1 Kelompok Jaga Mencoba Meraih Kelompok Lawan 
Berdasarkan dari hasil penelitian yang diperoleh oleh peneliti permainan tradisional gobag sodor membantu dalam proses perkembangan motorik kasar dimana dalam permainan ini anak-anak diharuskan bisa bekerjasama dengan anggota kelompok agar bisa melewati lawan yang menjaga benteng, yang nantinya anggota yang bermain bisa sampai ke akhir garis dan bisa menang. Ketika melewati lawan anak- anak harus bisa tangkas dan cepat berlari dan menghindar dari lawan yang berjaga dari itulah anak-anak dapat melatih motorik kasarnya seperti anak dapat melatih gerak tubuh, mengkoordinasi setiap anggota tubuh, menjaga keseimbangan ketika menghindar dari lawan dan berlari sambil melompat, selain mengembangkan motorik kasar anak-anak dapat melatih kerja sama, membuat strategi dan kepemimpinan. Sebelumya pendidik sudah menyiapkan untuk proses kegiatan pembelajaran seperti tahap persiapan, tahap awal, tahap pengembangan, dan tahap akhir.

\section{Kesimpulan}

Berdasarkan paparan data diatas dan pembahasan. Peneliti dapat menyimpulkan bahwa Permainan tradisional gobag sodor merupakan permainan yang dapat mengembangkan motorik kasar anak yaitu dapat mengkoordinasi gerak tubuh, menjaga keseimbangan, melompat, dan ketangkasan. Pada saat bermain anak-anak diharuskan untuk dapat berlari melawati lawan yang berjaga dan tidak boleh terkena lawan jika ingin memenangkan permainan dan sampai ke finish. Dengan kata lain dalam mengembangkan motorik kasar dengan permainan tradisional sangat membantu untuk mengembangkan motorik kasar anak usia dini.

Kegiatan permainan tradisional gobag sodor merupakan salah satu proses kegiatan belajar bagi anak untuk lebih mengetahui permainan tradisional dan memberikan anak pengalaman baru, sehingga anak akan bisa lebih mengenal permainan tradisional salah satunya permainan tradisional gobag sodor.

\section{Daftar Pustaka}

\section{Jurnal Artikel:}

Armen, Meiriani dan Apriyanti Rahmalia. "Pengaruh Permainan Tradisional Rondes Dan Gobak Sodor Terhadap Kemampuan Gerak Motorik Kasar Siswa Kelas V Sd." (2017). UNES Journal of Education 1. no. 4.

Erdiana, Lita. "Pengaruh permainan tradisional gobak sodor terhadap perkembangan motorik kasar dan sikap kooperatif anak TK kelompok B di kecamatan Sidoarjo." (2016). Jurnal Pedagogi 2. 
no. 3.

Hasanah, Uswatun. "Pengembangan Kemampuan Fisik Motorik Melalui Permainan Tradisional Bagi Anak Usia Dini." Jurnal Pendidikan Anak 5, No. 1 (19 Juni 2016).

Muslimah, Jamiatul. dkk. "Pola Asuh Orang Tua Dan Perkembangan Moral Anak Usia Dini (Studi Kasus di Tk Al-Ghazali Jl. Raya Nyalaran Kelurahan Kolpajung Kecamatan Pamekasan Kabupaten Pamekasan)". (2020). Kiddo: Jurnal Pendidikan Islam Anak Usia Dini. Vol 1. No 1.

Nurhayati, Iis. "Peran Permainan Tradisional Dalam Pembelajaran Anak Usia Dini (Studi di PAUD Geger Sunten. Desa Suntenjaya)". (2012). 1. no. 2252.

Siagawati, Moniqa. dkk. "Mengungkap Nilai-Nilai Yang Terkandung Dalam Permainan Tradisional Gobag Sodor." (2007). Indigenous. Jurnal Ilmiah Berkala Psikologi. Vol. 9. No. 1.

\section{Buku:}

Ardy Wiyani, Novan. Psikologi Perkembangan Anak Usia Dini. (2014). Yogyakarta: Gava Media.

Fadillah, M. Bermain dan Permainan Anak Usia Dini. (2017). Jakarta: Kencana.

Hasanah, Uswatun, dkk. Permainan Tradisional dan Permainan Modern untuk Anak Usia Dini. (2019). Lampung: CV. Iqro'.

Hayati, Sholatul. Tangkas Fisik-Motorik dengan Permainan Tradisional. (2018). Yogyakarta: Pustaka Pelajar.

Indah Rini, Julie. Aneka Permainan Anak-Anak Indonesia. (2010). Surakarta: Multi Kerasi.

Janice, J. Beaty. Observasi Perkembangan Anak Usia Dini. 7 ed. (2015). Jakarta: Kencana.

Khodijah. Konsep Dasar Pendidikan Prasekolah. (2012). Medan: Persana Mulia Sarana.

Kurniati, Euis. Permainan Tradisional dan Perannya dalam Mengembangkan Keterampilan Sosial Anak. (2017). Jakarta: Prenada Media Group.

Mulyani, Novi. Super asyik permainan tradisional anak Indonesia. (2016). Cetakan pertama. Baturetno, Banguntapan, Yogyakarta: Diva Press.

Mursid. Belajar dan Pembelajaran Paud. (2016). Bandung: PT Remaja Rosdakarya.

P. Ratu Bangsawan, Irwan. Direktori Permainan Tradisional Kabupaten Banyuasin (2019). Sumatra Selatan: Dinas Pendidikan. Pemuda. Olahraga. Dan Pariwisata Kabupaten Banyuasin.

Ricka Pratama, Lia. Perkembangan Anak. (2017). Metro Lampung: 
Laduny.

Rudiyanto, Ahmad. Perkembangan Bahasa Anak Usia Dini. , (2018). Lampung: Laduny.

- - - Perkembangan Motorik Kasar Dan Motorik Halus Anak Usia Dini. Labuhan Ratu: Darusalam Press, t.t.

Upton, Penney. Psikolgi Perkembangan. (2012). Jakarta: Erlangga. 